\title{
A Case of Ruptured Aneurysm of the Persistent Sciatic Artery Presenting Acute Lower Limb Ischemia
}

\author{
Noriyuki Shimizu, MD, Ph.D, Yuichi Izumi, MD, Ph.D, Katsuaki Magishi, MD, Ph.D, and Daiki Uchida, MD
}

Only 5 cases of ruptured aneurysm of the persistent sciatic artery have been previously reported to date. We experienced a case of ruptured aneurysm of the persistent sciatic artery presenting acute lower limb ischemia. Physical examination showed a pulsatile mass with a subcutaneous hemorrhage in the left buttock, drop foot and paresthesia of the foot due to limb ischemia. An enhanced computed tomography scan showed a ruptured aneurysm of the left persistent sciatic artery at the level of the greater trochanter. An exclusion of the aneurysm and creation of common iliac to popliteal artery bypass was performed as an emergency operation.

Key words: aneurysm of persistent sciatic artery, ruptured aneurysm, acute lower limb ischemia

CASE

A 75-year-old woman residing on an isolated island had a sudden onset of left buttock and left lower extremity pain. She was transferred to our hospital about 36 hours after the symptoms first appeared. Physical examination revealed a pulsatile mass with a subcutaneous hemorrhage in the left buttock, normal femoral pulse and absent popliteal and pedal pulse in the left lower extremity, and drop foot and anesthesia of the toes on the left. The ankle brachial pressure index (ABI) on the left was 0.36 .

An enhanced computed tomography (CT) scan showed a ruptured aneurysm of persistent sciatic artery (PSA) measuring $6 \mathrm{~cm}$ and associated with a hematoma at the level of the greater trochanter (Fig. 1A). The left superficial femoral artery and profunda femoris artery were hypoplastic (Fig. 1B).

Department of Cardiovascular Surgery, Nayoro City General Hospital, Nayoro, Hokkaido, Japan

Received: January 29, 2008 Accepted: December 16, 2008 Address for reprint requests to Noriyuki Shimizu, MD, Ph.D: Department of Cardiovascular Surgery, Nayoro City General Hospital, Nishi 7 jo Minami 8 chome 1, Nayoro, Hokkaido 096-8511, Japan

Tel: +81-1654-3-3101, Fax: +81-1654-2-0567

E-mail: nshimizu@asahikawa-med.ac.jp
Because the patient's symptoms were thought to be due to the ruptured aneurysm and acute arterial occlusion, an emergency operation was performed. Firstly, the left common, internal and external iliac arteries were exposed through a retroperitoneal approach. It was bound that the left-side PSA arose from the internal iliac artery (IIA), the IIA was ligated to interrupt the flow into the aneurysm. Secondary, the left popliteal artery was exposed. The artery coursed on the outside rather than along the normal course. When the artery was incised on the above knee, the artery was occluded by a thrombus on the proximal and the distal side of the incision portion. We removed the thrombus only on the distal side of the artery, and a common ilio-to-popliteal artery bypass (above knee) was performed with a 6-mm knitted Dacron graft (Fig. 2). Because the IIA was ligated and the proximal side of the above knee popliteal artery was occluded by the thrombus, the aneurysm was excluded.

Thirdly, the patient was turned from a supine to a right lateral decubitus position, and an oblique incision was made over the left buttock. The ruptured aneurysm of the PSA was then exposed by splitting the gluteus maximus muscle. When the aneurysm was exposed, some thrombus existed in the aneurysm and the aneurysm was excluded. After the operation, the ABI on the left was 1.09, but drop foot and anesthesia of the toes on the left persisted. An enhanced CT scan showed no rem- 

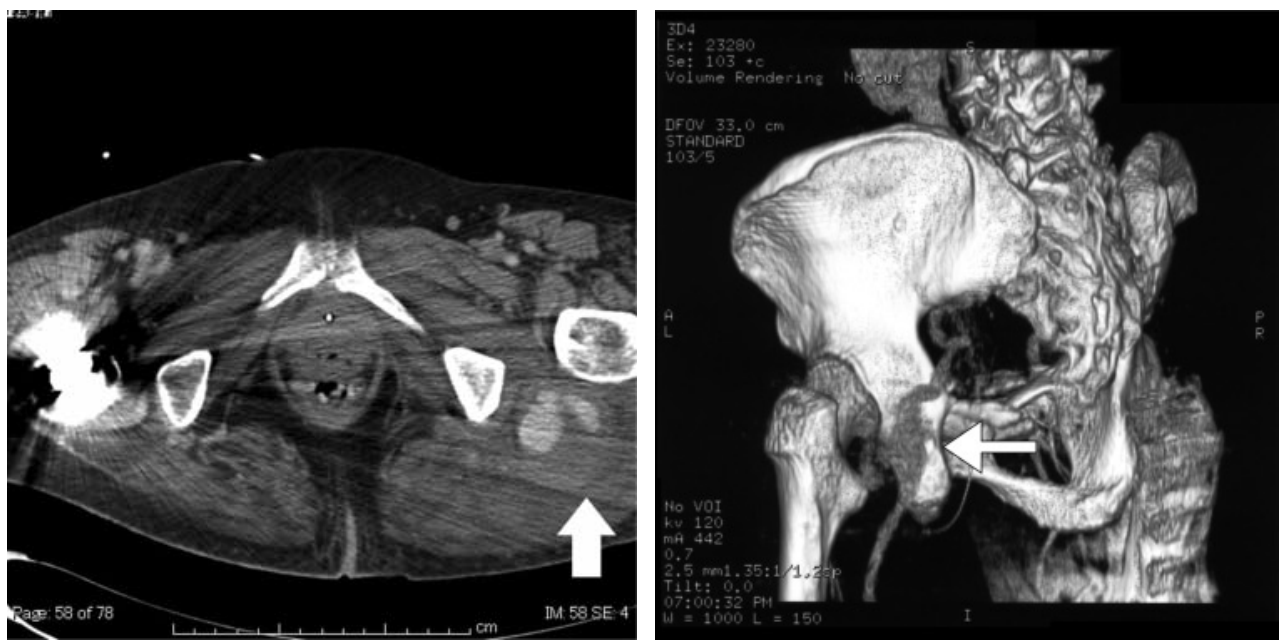

A $\mid$ B

Fig. 1 Enhanced computed tomography scan shows an aneurysm of the persistent sciatic artery surrounded by a hematoma in the left buttock (A). Three-dimensional reconstructed enhanced computed tomography scan shows an aneurysm of the left persistent sciatic artery at the level of the greater trochanter $(\mathbf{B})$.

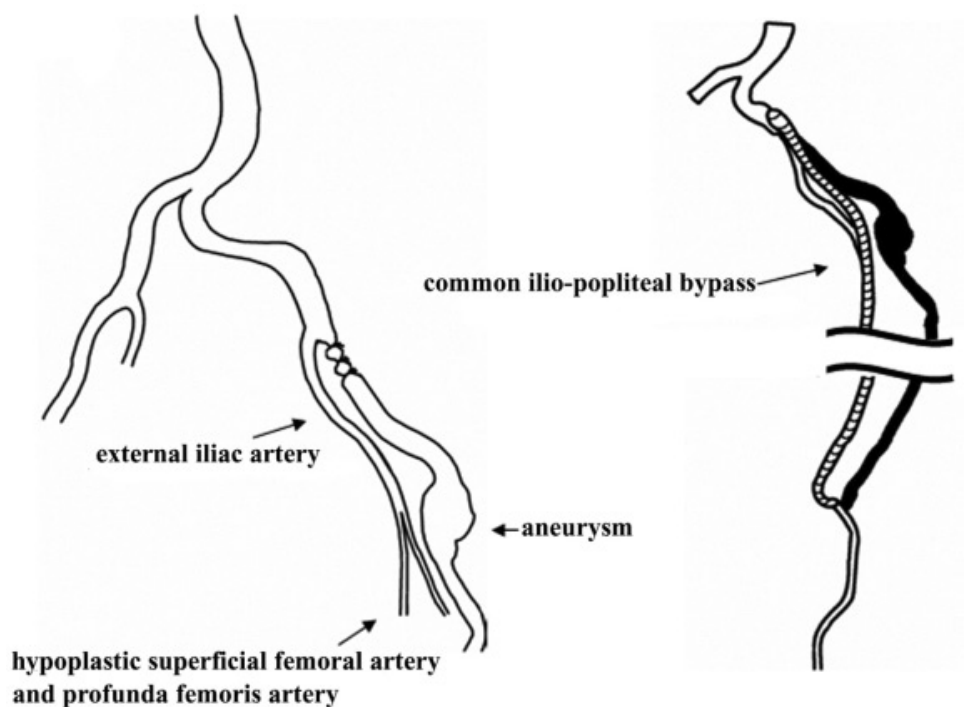

Fig. 2 Schematic drawing of the operative procedure in which ligation of the internal iliac artery to interrupt the flow of the aneurysm with a common ilio-popliteal bypass was performed.

nant of aneurysm and a patent bypass graft. The patient was transferred to the regional hospital for rehabilitation. The patient gradually recovered to walk at 1 year and 5 months after surgery.

\section{Discussion}

The sciatic artery is a main artery of the lower extremity during early-stage embryonic development. Nor- mally, the femoral artery, as an extension of the external iliac artery, develops and supersedes the sciatic artery by the 3rd fetal month. PSA is a failure by the sciatic artery to regress during this period. The incidence of PSA was $0.025 \%-0.04 \%$ in angiographic studies. ${ }^{1)}$ Patients with PSA are prone to develop aneurysmal dilatation, and the incidence of aneurysm formation in these patients is high accounting approximately $40 \% .^{2)}$ Recently, the reports relating to PSA have increased because of advancements 
Table 1 Summary of cases of ruptured aneurysm of persistent sciatic artery

\begin{tabular}{|c|c|c|c|c|c|}
\hline Author (s) & Age (yr) & Sex & Side & Symptoms & Operative procedure / Result \\
\hline Fagge, $1864^{3)}$ & 48 & $\mathrm{~F}$ & $\mathrm{R}$ & Thigh pain for 3 months & Death \\
\hline Thomas, $1978^{7)}$ & 53 & $\mathrm{M}$ & $\mathrm{L}$ & Pulsatile mass, claudication, leg pain & Exclusion \\
\hline Sahara, $1986^{8)}$ & 72 & $\mathrm{~F}$ & $\mathrm{R}$ & Pulsatile mass, pain, shock & Resection + internal ilio - popliteal artery bypass \\
\hline Hessling, $1987^{9)}$ & 57 & M & $\mathrm{L}$ & Pulsatile mass, claudication & Resection + interposition \\
\hline Ishida, $2005^{10)}$ & 65 & $\mathrm{~F}$ & $\mathrm{R}$ & Sudden onset of buttock pain & $\begin{array}{l}\text { Exclusion }+ \text { common ilio - persistent sciatic } \\
\text { artery bypass }\end{array}$ \\
\hline Present study & 75 & $\mathrm{~F}$ & $\mathrm{~L}$ & $\begin{array}{l}\text { Sudden onset of buttock } \\
\text { and lower extremity pain }\end{array}$ & Exclusion + common ilio - popliteal artery bypass \\
\hline
\end{tabular}

of diagnostic study such as imaging modalities.

An aneurysm of the PSA is sometimes detected by arteriography or by the presence of a pulsatile gluteal mass, the symptoms of sciatic nerve compression, the absence of a femoral pulse and an intact popliteal pulse, and/or acute or chronic lower limb ischemia. ${ }^{2,3)}$

Although the treatments for aneurysm of PSA include resection, exclusion and embolization, the need for simultaneous revascularization must be evaluated, depending on the type of PSA. ${ }^{4,5)}$ Bower et al. ${ }^{6}$ classified PSA into complete and incomplete types. In the former type, the PSA is the main supply to the extremity and changes little in its course from the IIA to the popliteal artery, and the superficial femoral artery (SFA) is usually hypoplastic and provides only collateral vessels to the lower limb or is completely absent. Because the popliteal artery receives blood flow from only the PSA, when the PSA is treated, revascularization of the lower extremity is crucial. In the latter type, the PSA does not connect with the popliteal artery directly but the SFA does connect with the popliteal artery. In this incomplete type, revascularization of the lower extremity is not necessary.

In our case, we believe the complete type of PSA progressively degenerated, resulting in a ruptured aneurysm and acute limb ischemia due to the thrombus formation at distal segment of PSA on the side distal to the aneurysm of PSA. When a thrombectomy on only the distal side of the popliteal artery was performed, the path distal to the APSA to the popliteal artery remained occluded, so the APSA could be excluded by ligation of the IIA. There is some report that predisposing factor of an aneurysm of PSA may be chronic mechanical compression on PSA ${ }^{6)}$ however, to our knowledge, there is no report referred to the cause of a ruptured aneurysm of PSA. In our case, the patient did not develope foot necrosis after 36 hours from the onset of symptom. Because she had been chronic arteriosclerotic disease at lower thigh on postoperative $\mathrm{CT}$ scan, her foot assumed to have an ischemic tolerance. To our knowledge, ours is the first reported case of a ruptured aneurysm of PSA with acute lower limb ischemia.

\section{REFERENCES}

1) McLellan GL, Morettin LB. Persistent sciatic artery: clinical, surgical, and angiographic aspects. Arch Surg. 1982; 117: 817-22.

2) Ikezawa T, Naiki K, Moriura S, Ikeda S, Hirai M. Aneurysm of bilateral persistent sciatic arteries with ischemic complications: case report and review of the world literature. J Vasc Surg. 1994; 20: 96-103.

3) Martin KW, Hyde GL, McCready RA, Hull DA. Sciatic artery aneurysms: report of three cases and review of the literature. J Vasc Surg. 1986; 4: 365-71.

4) Brantley SK, Rigdon EE, Raju S. Persistent sciatic artery: embryology, pathology, and treatment. J Vasc Surg. 1993; 18: 242-8.

5) Becquemin JP, Gaston A, Coubret P, Uzzan C, Melliere D. Aneurysm of persistent sciatic artery: report of a case treated by endovascular occlusion and femoropopliteal bypass. Surgery. 1985; 98: 605-11.

6) Bower EB, Smullens SN, Parke WW. Clinical aspects of persistent sciatic artery: report of two cases and review of the literature. Surgery. 1977; 81: 588-95.

7) Thomas ML, Blakeney CG, Browse NL. Arteriomegaly of persistent sciatic arteries. Radiology. 1978; 128: 55-6.

8) Sahara T, Kato R, Hasegawa T, Uchiki K, Kazui S, Tsuchioka H. A case of a ruptured persistent primitive sciatic artery aneurysm. Rinsho Geka. 1986; 41: 1723-7.

9) Hessling KH, Szkandera J, Theron L. Pulsatile gluteal mass revealed as a false aneurysm of a persistent sciatic artery. A case report. S Afr Med J. 1988; 73: $245-6$.

10) Ishida $K$, Imamaki $M$, Ishida $A$, Shimura $H$, Miyazaki M. A ruptured aneurysm in persistent sciatic artery: a case report. J Vasc Surg. 2005; 42: 556-8. 